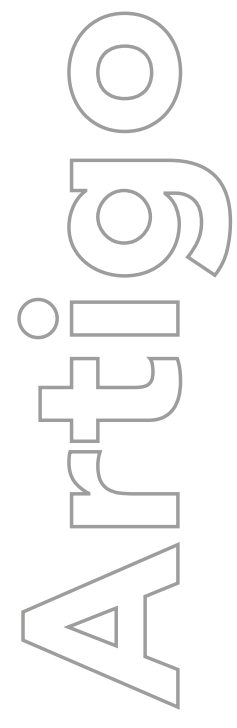

revista

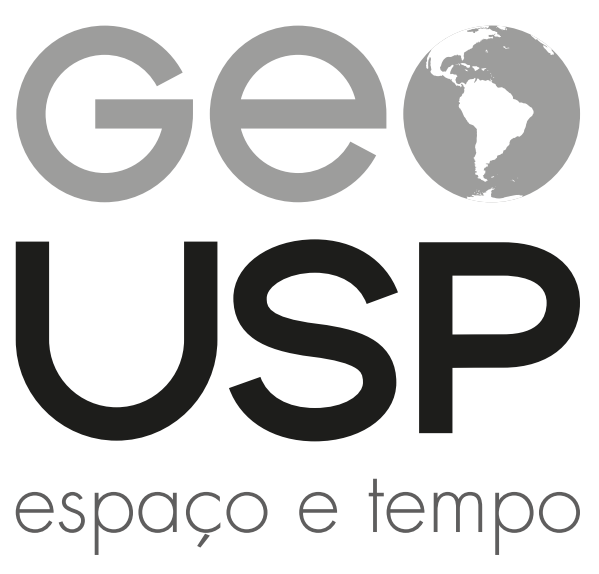

Volume $25 \cdot n^{\circ} 3$ (2021)

ISSN 2179-0892

\section{Por uma singularidade da Geografia: desenvolvimento do Pensamento Geográfico}

\section{Luline Silva Carvalho Santos}

Secretaria Estadual de Educação do Mato Grosso.

Cuiabá. Mato Grosso. Brasil

lulinescs@gmail.com

(100000-0002-2406-3108

e-182301

Como citar este artigo:

SANTOS, . S. C. Por uma singularidade da Geografia: desenvolvimento do Pensamento Geográfico. Geousp, v. 25, n. 3, e-182301, dez. 2021. ISSN 2179-0892. Disponível em: https://www.revistas.usp.br/geousp/article/ view/182301. doi: https://doi.org/10.11606/issn.2179-0892. geousp.2021.182301.

Disponível em: https://www.revistas.usp.br/geousp/article/ view/156773. doi: https://doi.org/10.11606/issn.2179-0892. geousp.2021.182301

\section{(c) (i)}

Este artigo está licenciado sob a Creative Commons Attribution 4.0 Licence 


\title{
Por uma singularidade da Geografia: desenvolvimento do Pensamento Geográfico
}

\section{Resumo}

A literatura contemporânea tem evocado como singularidade da Geografia a estruturação de uma forma de pensar específica denominada Pensamento Geográfico. Todavia, se há uma ampla defesa da Geografia como forma de pensar, contraditoriamente, ainda são poucos os trabalhos que conceituam o que é esse Pensamento Geográfico, seus processos de estruturação e constituição. Este artigo visa contribuir com o avanço do debate teórico reduzindo a lacuna sobre o tema na literatura brasileira. A discussão está balizada nas seguintes questões: o que é o Pensamento Geográfico? Como se desenvolve? Que processos cognitivos o caracterizam? Para tanto, realizou-se pesquisa bibliográfica nos campos da Psicologia e da Geografia relacionando a cognição humana e suas especificidades a partir da aprendizagem e da formação dos conceitos geográficos pelos indivíduos. Por fim, observou-se como essa relação culmina na constituição de uma forma singular de pensar.

Palavras-chave: Geografia. Cognição. Pensamento Geográfico.

\section{For a singularity of Geography: development of Geographic Thinking}

\begin{abstract}
Contemporary literature has evoked as responsible for the singularity of Geography, the structuring of a specific way of thinking, called Geographic Thinking. However, if there is a wide defense of Geography as a way of thinking, in a contradictory way, there are still few works that conceptualize what this Geographic Thought is, its processes of structuring and constitution. In this sense, this article aims to contribute to the advancement of the theoretical debate by reducing the gap in the Brazilian literature on the topic. The proposed discussion is based on the following questions: what is Geographic Thinking? How does
\end{abstract}


it develop? What cognitive processes characterize it? To this end, bibliographic research was carried out in the fields of Psychology and Geography, relating human cognition and the specificities attributed to it from the learning and formation of geographical concepts by individuals. It was observed in the end, how this relationship culminates in the constitution of a singular way of thinking.

Keywords: Geography. Cognition. Geographic Thinking.

\section{Por una singularidad de la Geografía: desarrollo del Pensamiento Geográfico}

\section{Resumen}

La literatura contemporánea ha evocado como responsable de la singularidad de la Geografía, la estructuración de una forma específica de pensar, denominada Pensamiento Geográfico. Sin embargo, si existe una amplia defensa de la Geografía como forma de pensar, de manera contradictoria, aún son pocos los trabajos que conceptualicen lo que es este Pensamiento Geográfico, sus procesos de estructuración y constitución. Así, este artículo tiene como objetivo contribuir al avance del debate teórico mediante la reducción de la brecha en la literatura brasileña sobre el tema. La discusión propuesta se basa en las siguientes preguntas: ¿Qué es el Pensamiento Geográfico? ¿Cómo se desarrolla? ¿Qué procesos cognitivos lo caracterizan? Para ello, se llevó a cabo una investigación bibliográfica en los campos de la Psicología y la Geografía, relacionando la cognición humana y las especificidades que se le atribuyen a partir del aprendizaje y formación de conceptos geográficos por parte de los individuos. Finalmente, se observó cómo esta relación culmina en la constitución de una forma de pensar singular.

Palabras clave: Geografía. Cognición. Pensamiento geográfico. 


\section{Introdução}

Neste artigo, considera-se que, por meio de múltiplas abordagens teóricas e percursos metodológicos que se desenvolveram ao longo da história da Geografia, edificou-se uma conceituação própria que, mobilizada como instrumento cognitivo na leitura e análise dos fenômenos, permite compreender os fatos numa perspectiva centrada essencialmente na questão espacial. Essa capacidade cognitiva denomina-se pensamento geográfico.

Julga-se pertinente enfatizar que não é um objetivo tratar aqui dos vários significados historicamente envolvidos no rótulo Geografia ou das visões que se sedimentaram ao longo do tempo (Moraes, 2005). Logo, a designação pensamento geográfico não é analisada em sua dimensão filosófica, pois isso contemplaria "um conjunto de discursos a respeito do espaço que substantivam as concepções que uma dada sociedade, num momento determinado, possui acerca do seu meio (desde o local ao planetário) e das relações com ele estabelecidas" (Moraes, 2005, p. 32).

Diferente disso, mas em diálogo intenso com essa dimensão filosófica, a questão central do artigo diz respeito ao desenvolvimento do pensamento - construir conceitos e operar com eles - a partir da internalização de conhecimentos geográficos. Dito de outro modo, estando este artigo vinculado à área da educação geográfica, o termo pensamento vincula-se ao campo da cognição e, por isso, pensamento geográfico designa um conjunto de operações mentais que se desenvolvem a partir da aprendizagem do conhecimento da Geografia e compreensão de sua base epistemológica tanto na educação básica como no ensino superior.

Parte-se das premissas de que existe uma estrutura conceitual que sustenta o que se denomina Pensamento Geográfico e de que ela há de ser então o elemento balizador de todas as reflexões e ações que se almeja adjetivar como geográficas ou pertencentes à Geografia e também da prática profissional na área. Embora tais afirmações soem óbvias, observa-se na Geografia uma expressiva confusão permeada por dissensos quanto ao que lhe é próprio. Algumas indagações suscitadas são: o que identifica a Geografia como área do conhecimento? Que conceitos e princípios estão generalizados pelas teorias dessa ciência? $\bigcirc$ que são conhecimentos específicos da Geografia? Tais questões geram desafios no âmbito epistemológico e que reverberam na prática profissional.

No contexto em que se desenvolve a prática dos professores de Geografia, por exemplo, essas indagações, cujas respostas são às vezes negligenciadas, têm contribuído nos últimos anos para que a Geografia tenha sua relevância questionada. Logo, os docentes dessa área parecem ser substituídos por licenciados e técnicos de outras disciplinas, bem como a própria ciência parece não oferecer nenhuma contribuição exclusiva, tendo seu aporte teórico confundido ao de outras áreas, em especial história e ciências, por abordarem temas semelhantes. Realidade semelhante se aplica aos bacharéis, que comumente têm seu exercício profissional questionado quanto a suas atribuições e capacitações.

Essas questões mostram a necessidade de atestar a identidade da Geografia, bem como a contribuição singular dos profissionais da área. Este trabalho concorda com autores como Richter (2010), Callai (2013), González (2015), Miranda Arredondo (2016), Gomes (2017) e Cavalcanti (2019) de que a especificidade dessa ciência é a constituição do Pensamento Geográfico. 
Por essa concordância e sabendo que há uma ampla defesa da Geografia como forma de pensar, mas poucos ${ }^{1}$ trabalhos no Brasil, até este momento, que se ocuparam de conceituar o Pensamento Geográfico, entre eles, Gomes (2017) e Cavalcanti (2019), este artigo² visa oferecer elementos que contribuam com o avanço do debate teórico, ainda que como ponto de partida, para diminuir essa lacuna na literatura nacional.

Assim, este trabalho objetiva tratar de entendimentos que expressem o que são o Pensamento Geográfico e suas especificidades. Para tal, realizou-se pesquisa bibliográfica nos campos da Psicologia - vinculados especialmente à teoria histórico-cultural - e da Geografia, de modo a abordar os processos psicológicos e as especificidades da ciência que culminam na constituição do Pensamento Geográfico.

Para apresentação das discussões, dividiu-se este artigo em quatro seções. A primeira, apresenta as proposições introdutórias que norteiam o desenvolvimento do trabalho. $\mathrm{Na}$ segunda, buscou-se compreender aspectos gerais do pensamento, bem como os processos de estruturação do Pensamento Geográfico. Na terceira, apresenta-se uma base conceitual mínima capaz de sustentar a análise a partir dessa forma de pensar. Na última seção, há uma síntese do Pensamento Geográfico e de sua relevância para a identidade da ciência.

\section{Pensamento Geográfico: questões preliminares}

Como sinalizado na introdução deste trabalho, a Geografia como forma de pensar é uma compreensão de diferentes autores, tais como os citados acima. Ao longo da maturação do debate sobre o tema, as pesquisas adotaram diferentes denominações para o processo, destacando-se as expressões Pensamento Geográfico e Raciocínio Geográfico. Seu uso indiscriminado implicou uma fragilização teórica e, às vezes, da própria identidade geográfica. Por essa razão, precede as demais discussões deste artigo uma justificativa objetiva do uso da expressão Pensamento Geográfico para designar o desenvolvimento cognitivo mediado por conceitos geográficos.

Em trabalho recente, Santos, L. e Souza, V. (2021) dedicaram-se a distinguir, entre as possibilidades existentes, o pensamento e o raciocínio. Nas palavras dos autores, o pensamento é uma operação mental que "abrange uma série de processos psicológicos que são chamados de raciocínio" (Santos, L.; Souza, V., 2021, p. 10). Nessa perspectiva o raciocínio é parte do pensamento e se consolida em vários atos intelectuais internamente conectados que atuam como condutores para a formação dos conceitos. Sendo os conceitos uma função superior e a estrutura mais elaborada do pensamento, não é possível tratar o raciocínio como uma função mental à parte e independente do ato de pensar. Por isso, reafirma-se a proposição dos autores, de que a operação mental vinculada ao conhecimento geográfico se refere ao Pensamento Geográfico.

Para compreender a constituição do Pensamento Geográfico, cabe retomar alguns aspectos gerais do pensamento. $\bigcirc$ pensamento se configura num diferencial do homem em relação aos demais animais, estruturando-se por meio de operações racionais que são

1 Ressalve-se que, sendo um tema recente no Brasil, é natural que ainda seja objeto de poucos trabalhos, pois a maturidade teórica depende do desenvolvimento de pesquisas e, é claro, de tempo.

2 Este artigo é fruto da tese de doutoramento da autora, defendida no ano de 2020. 
comuns a todos os indivíduos e subsidiam várias habilidades, além de atuar como fio condutor para que o pensamento alcance a construção de conceitos.

Recorre-se à psicologia, em especial à teoria histórico-cultural, para fundamentar a perspectiva de que os conceitos se consolidam como o nível mais elevado do pensamento e se originam de uma generalização. Esse processo é mediado pelos signos. As proposições de Vigotski (2000, p. 167) e seus contemporâneos Smirnov et al. (1969) enfatizam que os conceitos podem ser cotidianos ou científicos, mas se constroem mutuamente numa relação conjunta.

O processo de maturação dos conceitos foi dividido por Vigotski (2000) em três estágios principais: sincrético, complexos e conceito. Entre o pensamento sincrético e o pensamento por complexos, desenvolvem-se os chamados conceitos cotidianos, que constroem generalizações a partir do concreto. Apenas os conceitos científicos se constituem como autênticos. Neles estabelecem-se generalizações a partir das generalizações construídas anteriormente. Assim, tem-se um conceito quando "uma série de atributos abstraídos - um conceito cotidiano - torna a se sintetizar e quando a síntese abstrata obtida se torna forma basilar de pensamento com o qual o indivíduo percebe e toma conhecimento da realidade que o cerca" (Vigotski, 2000, p. 226). Ao direcionar intencionalmente sua atenção para os atributos, sintetizá-los e simbolizá-los, surge o verdadeiro conceito científico (abstrato e teórico). Nesse sentido, o pensamento se torna mais complexo por meio da (re)construção dos conceitos.

Sobre os aspectos gerais do pensamento, cabe destacar ainda que conforme explica Vigotski (2000, p. 360), existe uma relação entre os conceitos, sendo que "a própria natureza de cada conceito particular já pressupõe a existência de um determinado sistema de conceitos, fora do qual ele não pode existir". Assim, os conceitos existem dentro de um sistema havendo alguns mais abrangentes e outros menos. Por isso, todo conceito deve ser considerado em sua relação com os demais conceitos pertencentes ao seu sistema.

Após essa breve retomada dos aspectos gerais do pensamento que permitiu apontar como os conceitos se desenvolvem ao longo da vida e existem numa relação de sistema, estabelecendo conexões diretas com o conhecimento acessado, o entendimento desenvolvido neste artigo é que o Pensamento Geográfico ocorre a partir da mobilização de uma série de operações racionais e da aprendizagem do conhecimento específico. Essa conjuntura promove a formação de conceitos, que somados aos princípios basilares dessa ciência, culminam no pensamento conceitual. Logo, numa forma única de analisar fenômenos, estruturar questões e buscar soluções.

Nesse sentido, ajuíza-se que para a constituição do Pensamento Geográfico é necessário assegurar que efetivamente se alcancem dois aspectos: (1) a aprendizagem do conhecimento geográfico e a consequente construção dos conceitos e (2) a compreensão dos conceitos em seu sistema. Ambos os aspectos estão conectados e constituem o Pensamento Geográfico, como se explica adiante.

A constituição de generalizações mais sólidas que se materializam na formação de conceitos verdadeiros, vincula-se ao primeiro aspecto destacado, ou seja, à aprendizagem do conhecimento específico da Geografia. A relevância do conhecimento teórico específico tem sido sinalizada ao longo dos anos por diferentes autores, como Chauí (2000), Shulman (2014), Libâneo (2008) e Cavalcanti (2012). 
Pensando seu papel na análise dos fenômenos pela ciência, Chauí (2000, p. 198) explicita que o conhecimento teórico de uma área dá bases a "explicação, descrição e interpretação geral das causas, formas, modalidades e relações de um campo de objetos, conhecidos graças a conhecimentos específicos, próprios à natureza dos objetos investigados".

Shulman (2014), Libâneo (2008) e Cavalcanti (2012) contribuem ao pensar sobre esse conhecimento e sua relevância na ação docente. Convergem na proposição de que a docência requer conhecimentos que permeiam diferentes dimensões, sendo que a dimensão do conhecimento específico é a base mínima para o exercício de ensino.

A cognição do conhecimento específico da Geografia ultrapassa a apreciação superficial das teorias geográficas em si, pois contempla a aprendizagem de sua base epistemológica e, consequentemente, o desenvolvimento de seus conceitos próprios e domínio dos métodos utilizados por ela no desenvolvimento de suas investigações. ${ }^{3}$

Estabelecendo aproximações com os demais autores citados, Cheptulin (1982) afirma que o desenvolvimento das formas do pensamento vincula-se ao desenvolvimento do conhecimento e a sua passagem por certos estágios. À medida que se alcançam estágios superiores, amplia-se a capacidade de identificar novas relações e ligações.

As colocações apresentadas aqui atestam a relevância da aprendizagem do conhecimento específico na constituição do Pensamento Geográfico, já que é a partir de sua internalização que se transformam noções em verdadeiros conceitos capazes de atuar como instrumentos mentais para análise dos fenômenos numa perspectiva geográfica.

O segundo aspecto constituinte do Pensamento Geográfico é a necessidade de que os conceitos geográficos sejam tomados num sistema. Além da aprendizagem dos conhecimentos específicos que culminam no desenvolvimento de conceitos geográficos, é preciso considerá-los na totalidade de um sistema com relações de equivalência, complementariedade e hierarquia.

Considerando sistemas de conceitos e a construção da análise do espaço, Golledge, Marsh e Battersby (2007) afirmam que os conceitos se dão numa relação cuja compreensão de um depende necessariamente do outro. Assim, os autores pontuam, por exemplo, que é preciso entender localização, distribuição, rede e região para compreender distâncias, centros e periferias e conexões.

A concepção de sistema de conceitos permite a teorização de fenômenos e sua leitura a partir da especificidade da Geografia, além de sustentar o entendimento de que o Pensamento Geográfico mobiliza uma conjuntura conceitual mínima viabilizando um modo próprio de analisar os fatos.

Após essas questões preliminares sobre a constituição do Pensamento Geográfico, encaminham-se as discussões seguintes e a síntese do processo, como se vê no Sistema Conceitual 1, que pode ser descrita assim: o Pensamento Geográfico se concretiza a partir da constituição de um sistema de conceitos que se amplia e torna mais consistente à medida que o indivíduo acessa conhecimentos específicos e compreende a base epistemológica de sua ciência (estruturas e propósitos da disciplina, princípios da organização conceitual e da investigação geográfica).

3 No caso da Geografia, é preciso cautela quanto a possíveis confusões sobre o que lhe é específico, pois, na análise dos fenômenos, essa ciência às vezes recorre a conhecimentos de outras áreas, cuja apropriação não os torna geográficos; por essa razão, precisam ser usados sempre a serviço de uma análise geográfica. 


\section{Sistema Conceitual 1 - Constituição do Pensamento Geográfico}

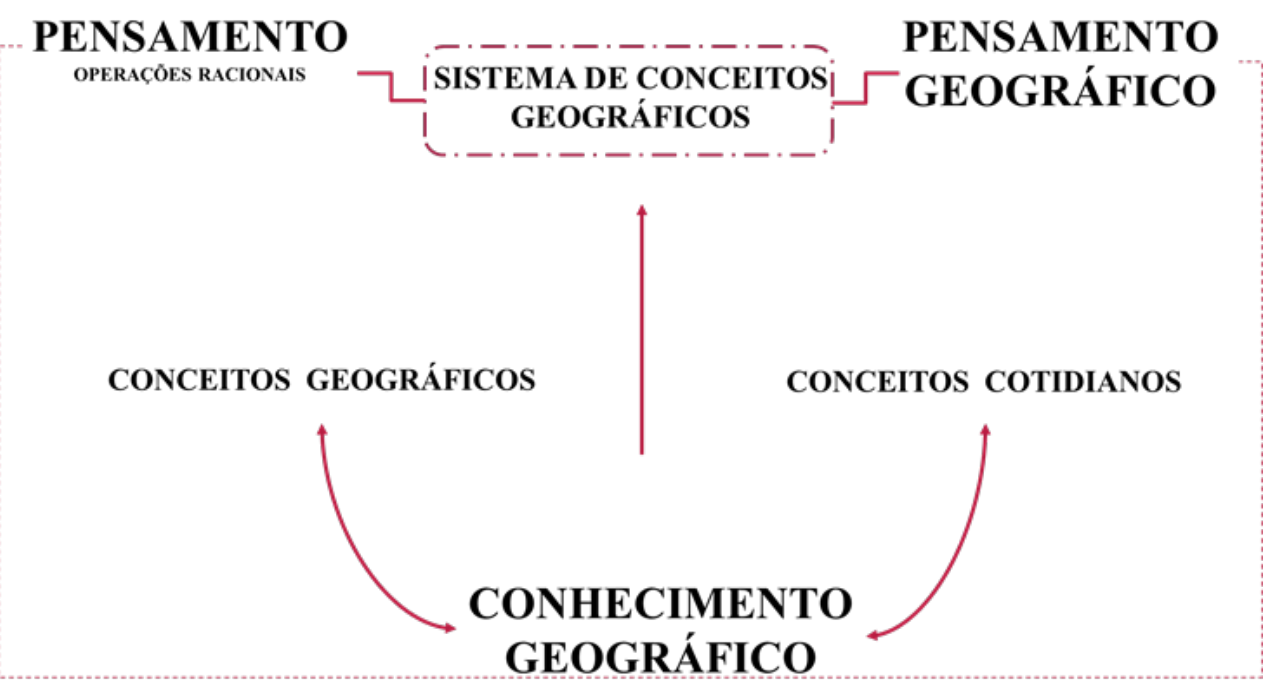

elaboração: A autora, 2019.

\section{Pensamento Geográfico: estrutura metodológica e sistema conceitual}

Ao longo de sua existência, a Geografia fez (re)interpretações significativas de seus conceitos, e em diferentes momentos emergiram novas generalizações na busca de explicar a ordem espacial. Parte-se desse fato para ressalvar que não é o objetivo deste artigo estabelecer um padrão de sistema conceitual geográfico pronto e encerrado que seja suficiente para analisar todos os problemas. Longe disso, entende-se que o sistema conceitual geográfico é construído constantemente, por isso, não se trata de uma tentativa de encerrar o debate na ciência, mas de contribuir para preencher lacunas na constituição e na operação com o Pensamento Geográfico.

Dialogando com as proposições de um Pensamento Geográfico baseado no desenvolvimento de conceitos, na literatura brasileira destaca-se os modelos teóricos de Moreira (2015), Haesbaert (2014) e Ascenção e Valadão (2014), ${ }^{4}$ que apresentam trabalhos em que propõem a compreensão dos fatos a partir de princípios e sistemas de conceitos geográficos.

Os três trabalhos se distinguem em diferentes pontos, inclusive no nível de maturidade no que tange ao desenvolvimento teórico. Contudo, respeitando suas particularidades, identificam-se dois elementos que permitem generalizá-las e apontá-las como representantes de um caminho para operação com o Pensamento Geográfico.

$\bigcirc$ primeiro elemento é que os três têm como centralidade a análise dos fenômenos a partir do espaço. Para isso, os autores afirmam a relevância e a relação com outros conceitos e propõem caminhos metodológicos para assegurar a análise geográfica do fenômeno. $\bigcirc$ segundo é a mobilização do pensamento a partir de um sistema de conceitos geográficos. É pertinente mencionar que os sistemas propostos são diferentes em cada pesquisa, porém convergem no entendimento de que o Espaço Geográfico apresenta generalização mais abrangente e, portanto, se constitui como conceito dominante.

4 Não se pretende esgotar a discussão sobre esses modelos e sua aplicabilidade, mas apenas ilustrar compreensões que dialoguem com o entendimento proposto aqui. 
Tomando por base esses modelos, bem como a literatura investigada para desenvolver este trabalho, segue-se um esforço para debater a questão e apresentar um sistema conceitual que se julgou a base da construção de todos os demais conceitos que são escopo para interpretar os fenômenos na perspectiva da Geografia.

Assim, almeja-se apontar, segundo entendimento advogado neste trabalho, um sistema conceitual fundante para a operação com o Pensamento Geográfico, sem excluir outros sistemas que possivelmente considerem outros conceitos, mas guardem em sua análise a questão espacial.

A reflexão sobre o sistema conceitual geográfico exige claramente uma demarcação de método. Assim, é importante enfatizar que, possivelmente, a escolha do método influenciará os caminhos e conceitos mobilizados na análise do fenômeno. Essa questão, no entanto, não visa legitimar "todas as pesquisas" como geográficas e ter como justificativa para as diferenciações entre elas o método. Até porque, já se pontuou antes que a ciência geográfica se preocupa em compreender as relações que se dão no espaço e são mediadas por ele, por isso, independentemente do método, deve-se dar prioridade a essa preocupação.

Do ponto de vista materialista dialético adotado neste trabalho, o princípio da consciência e da compreensão de qualquer fenômeno pelo Pensamento Geográfico é a análise das categorias filosóficas espaço e tempo. Nessa perspectiva, espaço e tempo são fundantes, unem a mutação e a estabilidade de todo fenômeno e são formas de existência da matéria em movimento.

De acordo com Cheptulin (1982, p. 181), "cada formação material particular, enquanto parte do mundo material, possui uma certa extensão e está em correlação, de uma maneira ou de outra, com outros objetos e formações materiais particulares que a rodeiam". Isso significa dizer que as formações materiais têm uma extensão e uma duração existencial que se concretizam no espaço e no tempo, assim, "qualquer fenômeno é simultaneamente extenso e limitado por outras extensões; disposto em ordem, permanece e ao mesmo tempo se modifica" (Oliveira, 1988, p. 98).

Admitindo a relevância de ambas as categorias, vale a pena apresentar o argumento de Oliveira (1988): apesar da relação indissolúvel entre espaço e tempo, eles têm características específicas. Assim, sem reduzi-los a uma definição, é possível pontuar que:

[...] a característica essencial do tempo reside no fato de estabelecer um elo entre a forma tempo de ser da matéria e o processo da transformação. Ainda que a passagem da não-existência à existência (e ao contrário) encontre sua consolidação espacial, é a referida passagem, como tal, que designa o curso do tempo. O espaço caracteriza a extensão e a estrutura do ser que está presente, o tempo caracteriza a duração e a estrutura do próprio processo de "adição" constante do ser de sua renovação, das transições entre o ser e o não-ser. [...] $\bigcirc$ movimento é a essência do tempo e do espaço. [...] $\bigcirc$ aspecto espacial de todo movimento, de toda variação, isolado do seu aspecto temporal (no plano abstrato) significa uma transformação naquilo que se apresenta, a parte temporal tomada no seu abstrato, isolada da parte espacial, é a aparição de uma coisa e a desaparição de outra, quer dizer, é uma transformação com a aparição de algo novo. O tempo está, portanto, relacionado com a transformação do vir a ser. Precisamente porque este processo de surgimento e desaparecimento não tem lugar num vazio, mas no seu presente, 
na realidade presente, é que o tempo se acha indissoluvelmente ligado ao espaço. As transformações temporais encontram sua consolidação nas transformações espaciais (Oliveira, 1988, p. 108-109).

As colocações de Oliveira (1988) mostram a relevância de compreender os fenômenos a partir dessas categorias. Assim, admite-se espaço e tempo como dimensões que se colocam como ponto de partida para entender a realidade na perspectiva geográfica. Essa compreensão alicerça-se na ideia de um espaço que não se resume a palco da história, ou mero receptáculo, mas que simultaneamente é condicionado e condiciona os fatos.

Esses fatos precisam ser interpretados também a partir de uma lógica temporal, permitindo o entendimento de conexões, vínculos e ações sociais que geriram os processos até se chegar à realidade presente. Assim, ao partir dessa premissa, advoga-se a existência de um sistema conceitual geográfico no qual a questão espacial aparece no centro da análise.

É pertinente enfatizar que ao pensar em um sistema conceitual geográfico, ou seja, na relação estabelecida entre unidades explicativas dos fenômenos, tendo como princípio a questão espacial, a referência é ao conceito de espaço geográfico e não a categoria filosófica espaço. Essa ressalva é importante, ao passo que, o uso indiscriminado do conceito espaço pode causar uma confusão teórica caso ele seja tomado em sua amplitude como sinônimo de espaço geográfico. Portanto, enfatiza-se a relevância das pesquisas em Geografia demarcar seu campo (espaço geográfico), a fim de que não se perca de vista a singularidade dessa ciência, que proporciona a leitura da composição espacial de determinado fenômeno a partir da relação entre as dimensões social e natural.

Moreira (2015) chama atenção para o fato de que a noção de espaço geográfico como chão da Geografia é um tema que perpassa variados discursos, de todos os tempos da ciência. Sendo assim, entende-se, que, em um sistema de conceitos geográficos, o espaço geográfico é o conceito dominante, subordinando os demais.

Atribui-se como função basilar da Geografia a compreensão das relações por meio do conceito de espaço geográfico, o que implica dizer que todos os demais conceitos se devem vincular totalmente a ele. Dito de outro modo, seja qual for o fenômeno e o conceito de análise a ser aplicado, ele deve guardar intensa relação com a ordem espacial. Essa relação assegura que o foco da análise seja sempre o arranjo espacial. Porém, como alerta Souza, M. (2016), por mais relevante que seja, um conceito sozinho nunca dá conta da leitura de um fenômeno; portanto, entender o espaço geográfico como um conceito de generalização mais ampla não significa que ele seja capaz de subsidiar a análise de um fenômeno sem mobilizar os demais conceitos de seu sistema. A operação mental com esse conceito confere identidade geográfica à reflexão, mas também acaba por demandar a interpretação a partir de outros conceitos importantes para a Geografia.

O conceito de espaço geográfico tem sido amplamente abordado por diferentes autores, pois a dimensão espacial confere a responsabilidade de desenhar as questões a ser realizadas para o fenômeno, e é esse também o caminho pelo qual nosso pensamento procura as respostas. $\bigcirc$ conceito de espaço geográfico assenta-se nas contribuições de Santos, M. (2017[1996]) e Moreira (2012). 
Em Milton Santos (2017[1996]), o espaço geográfico aparece como um conjunto indissociável de sistemas de objetos e sistemas de ações ${ }^{5}$ que o constitui como um conceito hibrido. Esse entendimento permite, por sua vez, reconhecer o que o autor chamou de categorias analíticas da Geografia: paisagem, configuração territorial, divisão territorial do trabalho, espaço produzido, rugosidades e formas-conteúdo, bem como pensar sobre os chamados recortes espaciais: região, lugar, redes e escalas.

Em resumo, o espaço geográfico é dado pela integração das formas físicas (objetos) com os aspectos sociais (ações). Assim, não se analisa esse espaço considerando apenas uma das dimensões; ao contrário, é preciso levar em conta a dependência entre elas, capaz de influenciar a localização, a distribuição e a conexões dos fenômenos. Portanto, devem-se considerar as formas e também as funções e os conteúdos atribuídos a elas por meio da ação movida por necessidades sociais.

Assim como Milton Santos (2017), Moreira (2015), concebe o espaço geográfico como parte basilar do processo de produção social e enfatiza a necessidade de entender a existência da relação entre a organização econômico-social e a organização espacial. Isso permite concluir que a Geografia é uma ciência social e, portanto, realiza uma análise espacial com base no entendimento dos processos de (re)produção das relações sociais.

Fazendo do espaço geográfico seu objeto de análise, a Geografia toma como objetivo compreender a natureza e as leis do movimento da formação econômico-social por intermédio do espaço. Por isso, o espaço geográfico é fundamentalmente um ente social, um espaço produzido que ultrapassa a função de suporte e/ou receptáculo. Nele, a natureza ${ }^{6}$ é uma condição concreta para a produção social. Em razão disso, o arranjo espacial se constrói a partir de elementos de ordem natural e elementos derivados do trabalho social (Moreira, 2015).

As colocações de Moreira (2015) acompanham o entendimento de Santos, M. (2017[1996]) ao atribuir qualificação geográfica ao espaço quando se levar em conta o espaço social, as dinâmicas naturais e seus condicionamentos relativos. Assim, é possível aproximar os autores no que tange ao entendimento de que a totalidade do espaço geográfico contempla a natureza e o homem e suas relações, que são essencialmente espaciais. No mesmo sentido, é possível inferir que o olhar para a relação homem-meio numa perspectiva espacial é que assegura a singularidade da Geografia frente a outros domínios de conhecimento.

Com base nessa discussão, reafirma-se o conceito de espaço geográfico como dominante no sistema de conceitos para o Pensamento Geográfico e, por isso, é correto dizer que toda investigação geográfica deve considerar a ordem espacial da dimensão física (sistema de objetos) e da dimensão social (sistema de ações) do fenômeno. Logo, não cabe à investigação geográfica estudar isoladamente fenômenos diversos que ocorrem no espaço, sejam eles geológicos,

5 A leitura de A natureza do espaşo permite retomar outras compreensões que foram propostas por Milton Santos (2017[1996]) e que, segundo o próprio autor, foram base para o aperfeiçoamento de sua proposta conceitual de espaço geográfico. Assim, no primeiro momento, ele entende o espaço como um conjunto de fixos e fluxos. Nessa construção teórica, que pode ser verificada em seu livro Por uma nova Geografia, de 1978, o autor se apoia na ideia de que os elementos fixos permitem ações que alteram o próprio lugar, bem como novos fluxos ou a renovação de velhos que o recriam e redefinem. Dessa forma, a ação integrada de fixos e fluxos define a realidade.

6 Vale reafirmar a relação homem-meio, na qual a "primeira natureza" não se enquadra como espaço geográfico, mas sem a qual o homem não poderia existir, pois ela integra a base da sociedade humana. 
geomorfológicos, climatológicos, populacionais, sociais etc. Para isso, existem ciências específicas que se ocupam dessa tarefa. $\bigcirc$ Pensamento Geográfico exige que tais fenômenos sejam analisados considerando as duas dimensões descritas acima, permitindo, portanto, a evidência da identidade da análise geográfica.

Quando se indica que o espaço geográfico é um conceito superior no sistema que está inserido, almeja-se reafirmar sua maior amplitude de generalização, bem como o entendimento de que ele abrange a compreensão dos demais conceitos que compõem o seu sistema. Assim, pode-se dizer que paisagem, território, lugar, região, redes e outros conceitos espaciais que possam vir a compor essa série são entendidos pelo conceito de espaço geográfico.

Como já destacado anteriormente, ainda que o espaço geográfico atue como conceito basilar da Geografia para a realização de uma análise, o pensamento mobiliza muitos outros conceitos vinculados ao de maior abrangência. Como nos explica Vigotski (2000), os conceitos não existem de maneira isolada. Qualquer operação intelectual pressupõe a mobilização de um sistema de conceitos no qual se estabelecem relações complexas e de interdependência. Desse modo, a existência particular de determinado conceito pressupõe a existência de um sistema, que no caso da Geografia tem como conceito superior o espaço geográfico.

Definir o espaço geográfico como conceito dominante do pensamento exige um segundo exercício que é o de buscar outros conceitos que são elementares nesse sistema. Isso implica destacar localização e escala geográfica como dois conceitos fulcrais - que são também princípios metodológicos - para a operação com o Pensamento Geográfico. Entende-se que ambos estruturam uma base metodológica para a análise geográfica de um fenômeno, ao passo que permitem identificar onde ocorre o fenômeno (localização) - e, consequentemente, sua distribuição por diferentes espaços e distâncias e as conexões estabelecidas - e a "extensão que lhe dá sentido" (escala geográfica) (Castro, I., 2014, p. 88).

Gomes (2009) também aponta a relevância da localização na definição da natureza e na constituição do diferencial da Geografia. $\bigcirc$ autor advoga que a reflexão que a Geografia tem a oferecer é de ordem espacial. Assim, a característica dessa ciência no estudo dos fenômenos é a análise de uma trama locacional que considera a lógica e as razões das distribuições. Essa concepção se assente na ideia de que há um arranjo espacial que é coerente e explicativo para a ocorrência de determinados acontecimentos. Assim, o tipo de questão a ser feita pela ciência geográfica diante de um fato é sempre quanto a dispersão espacial. Há, portanto, "uma análise geográfica quando o centro de nossa questão é a ordem espacial” (Gomes, 2009, p. 27), e o autor pontua ainda que:

Se a composição espacial colabora de forma essencial nos fenômenos, a análise das posições, das implicações relacionais delas no sistema locacional constitui uma dimensão fundamental para a compreensão dos fenômenos. Em outras palavras, isso funda um plano de análise autônomo, um verdadeiro campo de questões, um domínio epistemológico. Isso significa que ao ignorar ou negligenciar esse plano perdemos a oportunidade de desvendar toda uma ordem de sentidos e significações fundamentais que constituem os fenômenos (Gomes, 2009, p. 28). 
Como se vê nessa fala, o complexo sistema de posições e de localização deve ser valorizado na análise geográfica. Num trabalho de 2017, o autor conceitua a ideia de quadros geográficos como caminhos para se perceberem conectividades em múltiplas variáveis e reafirma o papel da Geografia no entendimento do jogo de posições a partir da localização para pensar relações e julgar proximidades ou distâncias.

Considerando as contribuições de Brunhes (1962), Moreira (2012) afirma que a localização é o ponto de partida para a leitura de um fenômeno na perspectiva geográfica, pois, sem ela, não há fenômeno geográfico. Porém, para que exista especificidade geográfica, a localização precisa ser compreendida em sua permanente interação com outras localizações, por isso, diz-se que ela se torna relevante ao ser percebida por meio da distribuição. Nesse sentido, a distribuição significa - "arranjo formado pelas interações e estado posicional das localizações" (Moreira, 2012, p. 83). O par localização-distribuição passa por uma metamorfose em que um termo qualifica o outro:

[...] tudo começa na localização. Em seguida, vista na sua repartição, a localização se multiplica para formar a distribuição. E localização e distribuição passam a mover-se como um par categorial diante do movimento do olhar recíproco. [...] Vista do andar da distribuição, a localização muda de natureza qualitativa, cada localização virando uma localização posicional relativamente à posição umas das outras dentro do tabuleiro da distribuição. E, vista do andar da localização posicional, a distribuição muda de natureza qualitativa igualmente, tornando-se um sistema de arranjo, um todo definido como uma estrutura de pontuações. $\bigcirc$ que era localização-distribuição, torna-se pois, posição-arranjo. Olhada agora do andar do arranjo, a localização posicional de novo muda qualitativamente; o quadro das posições vira uma situação. E, olhada do andar da situação, o arranjo, por sua vez, torna-se um sítio. $\bigcirc$ par posição-arranjo muda agora para o par situação sítio. Olhado, por fim, do andar do sítio, a situação vira uma configuração espacial. E, olhado da configuração espacial, o sítio torna-se uma escala. [...] Assim, o par situação-sítio vira o par configuração-escala (Moreira, 2012, p. 83-84).

Ao chegar à discussão da escala, ${ }^{7}$ é preciso considerar as orientações de Melazzo e Castro, C. (2007) sobre o cuidado de não tomar emprestada a noção de escala cartográfica como geográfica, uma vez que são diferentes, e isso implicaria adotar uma visão de espaço a priori, em seu sentido geométrico. A escala recebe um tratamento conceitual específico na Geografia, sendo um recurso para a leitura da amplitude dos processos.

A escala geográfica como recurso fundante da operação com o Pensamento Geográfico ultrapassa a medida matemática. Moreira (2012) explica que a escala geográfica nasce de um quadro composto por níveis que se entrecruzam. Ela se constitui como um plano vertical que compreende a sobreposição dos planos horizontais da extensão e da distância. Logo, a escala não pode ser pensada fora da localização e, além de um conceito, é um princípio metodológico

7 A escala geográfica é tomada aqui segundo a percepção de Haesbaert (2014), que a coloca ao lado do conceito de região, porque os processos de regionalização ou de identificação de diferenças espaciais representam uma espécie de recorte escalar do espaço geográfico. 
que permite considerar determinado fenômeno a partir do recorte que lhe dá sentido e verificar sua abrangência e suas conexões espaciais.

Em Castro, I. (2014), a escala geográfica implica tomar o fenômeno em sua extensão espacial, sopesando a melhor medida para sua análise e, portanto, os recortes significativos para a investigação. Assim, tratando-a numa perspectiva conceitual, Castro, I. (2014) pontua que a escala geográfica permite refletir sobre a polimorfia do espaço e as relações escalares envolvidas em sua análise.

Nesse sentido, entende-se aqui que a constituição do Pensamento Geográfico perpassa necessariamente a construção do conceito de espaço geográfico, o qual mobiliza como princípios metodológicos os conceitos de localização e escala, ou seja, a operação com esse modo de pensar na análise dos fenômenos implica localizar o fato - ou objeto - a ser analisado e delimitar sua extensão espacial e de análise.

Vale ressaltar que o processo de localização e definição da escala que o fenômeno será estudado por si só não dá conta de prover uma leitura geográfica, porém ele abre o caminho para que o sujeito que detém o conhecimento inicie processos mentais que o levem a construir dúvidas geograficamente pertinentes, elaborando suas primeiras análises. Esse processo pressupõe mobilizar outros conceitos geográficos para compreender melhor o evento observado (o conceito de paisagem, lugar, território e/ou outros conceitos que têm em seus genes uma relação espacial).

Considerando os elementos apresentados, entende-se que o Pensamento Geográfico está organizado como se apresenta no Sistema Conceitual 2. Não é objetivo deste artigo construir uma ideia de sistema encerrado. Os conceitos balizados (espaço geográfico, localização e escala) são pilares de fundamentação da análise geográfica, mas se desdobram em outros, por exemplo: território, paisagem e lugar. ${ }^{8}$ Respeitando as relações de hierarquia, cabe destacar que, além dos exemplos citados, podem derivar outros conceitos. Assim, num processo dinâmico, o sistema conceitual geográfico está em constante (re)elaboração, sem que isso signifique perder de vista sua relação com o espaço geográfico.

\section{Sistema Conceitual 2 - Sistema conceitual geográfico}

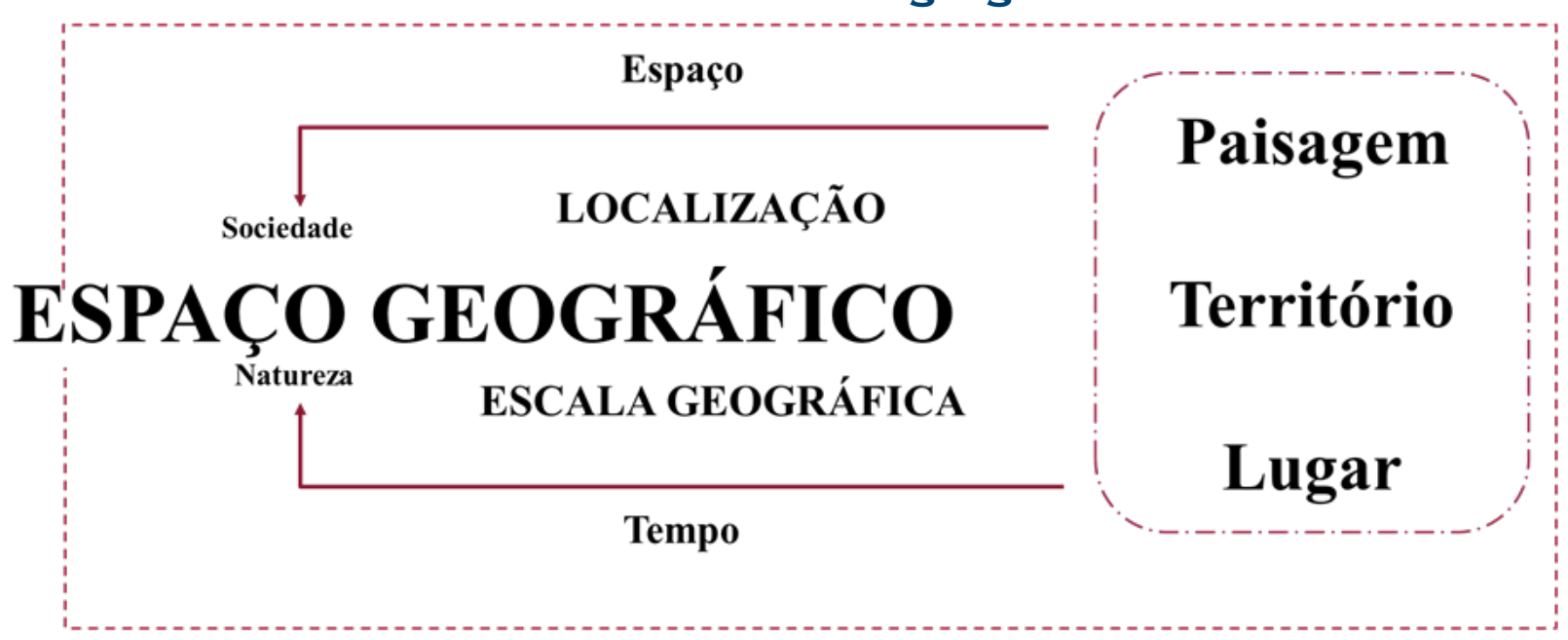

elaboração: A autora, 2019.

8 Sua sinalização se deve ao fato de serem reconhecidos por número expressivo de autores - que têm desenvolvido pesquisas com qualidade - como importantes ferramentas teóricas na explicação dos fenômenos a partir da questão espacial. 
Em resumo, o sistema conceitual acima almeja demarcar a relevância de ter as categorias filosóficas espaço e tempo como ponto de partida para compreender o espaço geográfico numa perspectiva materialista dialética, tomando como princípio analítico a localização e a escala geográfica do fato, para que se possam mobilizar outros conceitos sem perder de vista que as indagações a fazer diante de um fenômeno devem estar situadas na questão espacial.

Ao operar com o Pensamento Geográfico, o indivíduo compreende o espaço geográfico e se torna apto a analisar os fenômenos geograficamente e a propor ações. Smirnov et al. (1969) afirma que compreender permite, primeiramente, descobrir o que é o fenômeno. A partir disso, possibilita o entendimento da causa e consequências do fenômeno, a verificação de seu sistema de relações de causa e efeito, a origem e o processo de desenvolvimento do fenômeno, as relações essenciais e regulares dos objetos da realidade.

A compreensão, segundo elucidam Smirnov et al. (1969), consiste em esclarecer os fundamentos lógicos perguntando: por que e como isso aconteceu? Por que e de que é feita tal coisa? Assim, a compreensão exige o entendimento da estrutura do fenômeno, de que partes ele é composto, como cada uma das partes age e todas elas entre si. De acordo com os autores, a compreensão é o entendimento de todos os tipos de mecanismo que estruturam um organismo e sua atividade. Dessa forma, advoga-se que a compreensão se torna geográfica quando ela se dá pela via do Pensamento Geográfico e constrói questões específicas como as indicadas por Cavalcanti (2019): onde? Por que aí?

Diante das colocações apresentadas, destaca-se que o Pensamento Geográfico como caminho para compreender o espaço não é um estatuto pronto e acabado para pensar um objeto geográfico específico que pode ser ensinado. Tem-se, na verdade, um movimento processual que mobiliza conceitos próprios dessa ciência para pensar os diversos fenômenos que se materializam na interação entre a ação humana e a natureza e, consequentemente, se localizam, distribuem e conectam segundo uma lógica espacial, dando origem a um arranjo em que verificamos diferentes recortes, usos, agrupamentos, relações de poder, de identidade e outros.

\section{Considerações finais}

Ao final deste artigo, sabendo que a discussão apresentada está longe de esgotar o tema, retomam-se as principais contribuições compartilhadas e as reflexões que podem levar a pesquisas futuras.

A proposição norteadora desta análise foi a de que há um entendimento amplamente difundido nos últimos anos: a Geografia é capaz de desenvolver uma maneira específica de cognição, o chamado Pensamento Geográfico, que confere identidade e utilidade singular a essa ciência. Contudo, se é amplo o reconhecimento desse modo de pensar, contraditoriamente, são poucas as pesquisas que discutem mais profundamente os processos de sua constituição, desenvolvimento e caracterização. Nesses termos, o objetivo deste trabalho é responder o que é o Pensamento Geográfico e quais são suas especificidades.

Para tal, após balizar alguns elementos gerais da estruturação do pensamento, apresentaram-se dois elementos centrais para a constituição do Pensamento Geográfico: a aprendizagem 
do conhecimento geográfico e a consequente construção dos conceitos e a compreensão dos conceitos em seu sistema.

A partir disso, argumentou-se o que desenvolvimento do Pensamento Geográfico e a operação com ele exigem a constituição de um sistema de conceitos que se amplia e torna mais consistente à medida que o indivíduo acessa conhecimentos específicos da Geografia e compreende sua base epistemológica (estruturas e propósitos da disciplina e princípios da organização conceitual e da investigação geográfica). Esse sistema conceitual tem o conceito de espaço geográfico como o mais abrangente e se funda nos princípios metodológicos de localização e escala.

Dito isso, é possível fazer uma síntese do Pensamento Geográfico (Sistema Conceitual 3). Assim como nas demais propostas deste artigo, vale ressaltar que a sistematização apresentada não pretende definir um modelo rígido, mas indicar o processo de desenvolvimento do pensamento em sua forma mais geral e sinalizar uma estrutura mínima para a constituição do Pensamento Geográfico.

\section{Sistema Conceitual 3 - Estruturação do Pensamento Geográfico}

\section{PENSAMENTO}

OPERAÇÕES RACIONAIS

\section{$\longrightarrow$ CONHECIMENTÓO GEOGRÁFICO}

Base epistemológica

Princípios de análise

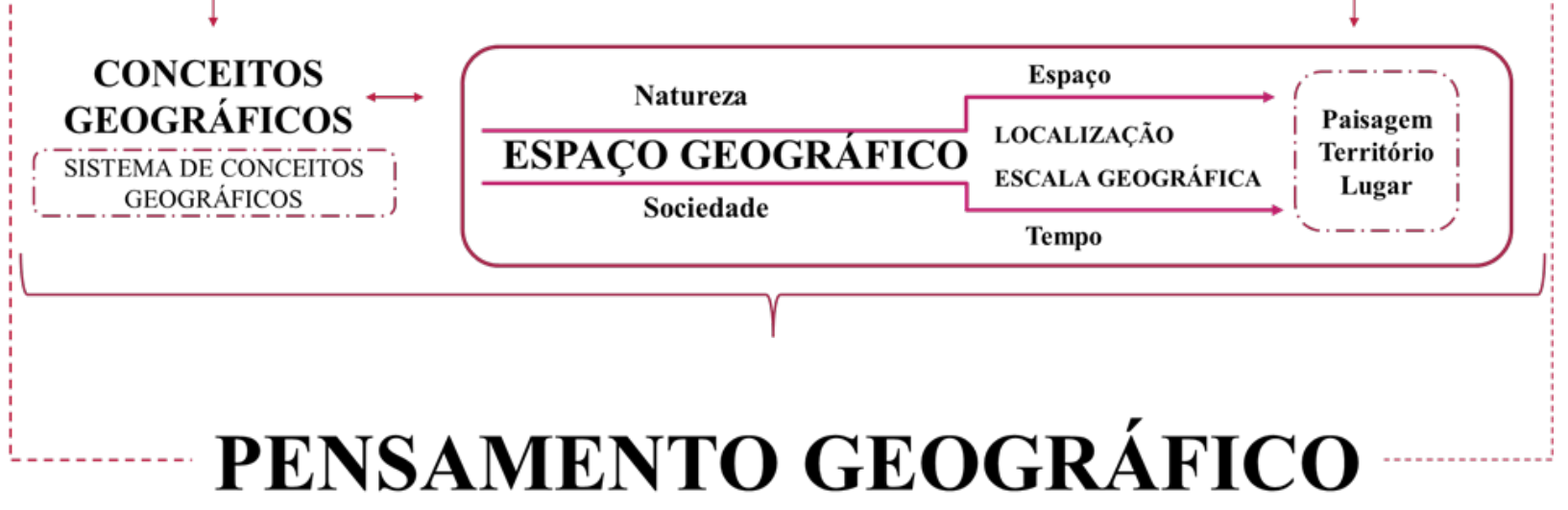

elaboração: A autora, 2019.

Apresentado o sistema conceitual, segue-se a conclusão: a análise de fatos por meio do Pensamento Geográfico se efetiva quando, aprendendo o conhecimento geográfico, o sujeito mobiliza as estruturas do pensamento e desenvolve um sistema de conceitos próprios dessa ciência. Essa construção ocorre num movimento dialético no qual se reconstroem os conhecimentos prévios, bem como o próprio sistema conceitual, agora de forma mais abrangente.

Vale lembrar que o ato de pensar envolve o raciocínio, logo, na leitura geográfica, aplicam-se diferentes operações racionais. Mas o que atribui identidade geográfica ao pensamento é fazer uso dessas operações para indagar o fenômeno por meio de uma base conceitual geográfica que tem no espaço geográfico seu pilar central. Por isso, infere-se que, quanto maior o nível de 
elaboração do sistema de conceitos geográficos - que se deve à ampliação da base epistemológica da Geografia -, maior será também a probabilidade de que a partir dele os indivíduos compreendam as dinâmicas de (re)constituição, (re)estruturação, (re)organização e manutenção de determinados fenômenos espaciais.

Acredita-se ter mostrado que o Pensamento Geográfico confere identidade e utilidade singular à atuação profissional em Geografia. É por meio desse pensamento, construído continuamente, que se torna possível responder o que identifica a Geografia como ciência, logo, seu desenvolvimento e/ou ampliação na formação inicial deve ser objetivo primordial nos cursos de graduação.

Por fim, ao expressar a relevância do Pensamento Geográfico, a pergunta que encaminha debates posteriores é: os processos formativos que os futuros profissionais em Geografia têm acessado concorrem efetivamente para o desenvolvimento do Pensamento Geográfico e, por conseguinte, para reafirmar a especificidade da Geografia? Daí derivam outras questões subjacentes, mas também muito importantes: a conjuntura dos cursos de licenciatura e bacharelado em Geografia concorre para a aprendizagem de sua base epistemológica ou, inversamente, contradiz a identidade geográfica e concorre para a conservação e/ou constituição de incoerências epistemológicas? O geógrafo expressa conhecimentos que diferenciem sua contribuição analítica da de outros profissionais?

Somadas às reflexões feitas neste artigo, essas questões levam em conta a necessidade de reafirmar a relevância da Geografia e sua especificidade. Por saber que todos os temas estudados nessa ciência são também objeto de investigação de outros domínios científicos, que todos os conteúdos ensinados também são tratados em outras disciplinas escolares, insiste-se em que a especificidade da Geografia não está na particularidade de um objeto de análise ou de conteúdo, mas sim na abordagem dos fenômenos a partir do Pensamento Geográfico, que mobiliza um sistema conceitual próprio e tem no espaço geográfico o conceito mais abrangente.

\section{Referências}

ASCENÇÃO, V. O. R.; VALADÃO, R. C. Professor de Geografia: entre o estudo do fenômeno e a interpretação da espacialidade do fenômeno. In: COLOQUIO INTERNACIONAL DE GEOCRÍTICA, 13., 2014, Barcelona. Anais... Barcelona: Universitat de Barcelona, 2014. p. 1-14. Disponível em: http://www.ub.edu/geocrit/coloquio2014/Valerie\%20 de\%20Oliveira\%20y\%20Roberto.pdf. Acesso em: 22 fev. 2021.

BRUNHES, J. A geografia humana. Rio de Janeiro: Fundo de Cultura, 1962.

CALLAI, H. C. A formação do profissional da geografia. ljuí, RS: Unijuí, 2013.

CASTRO, I. E. Escala e pesquisa na geografia: problema ou solução? Espaço Aberto, Rio de Janeiro, v. 4, n. 1, p. 87-100, 2014. Disponível em: https://revistas.ufri.br/index. php/EspacoAberto. Acesso em: 22 fev. 2021.

CAVALCANTI, L. S. Pensar pela geografia: ensino e relevância social. Goiânia: CEA Alfa Comunicação, 2019.

CAVALCANTI, L. S. O ensino de geografia na escola. Campinas, SP: Papirus, 2012.

CHAUÍ, M. Convite à filosofia. São Paulo: Ática, 2000. 
CHEPTULIN, A. A dialética materialista: categorias e leis da dialética. São Paulo: Alfa-Omega, 1982.

GOLLEDGE, R.; MARSH, M.; BATTERSBY, S. Matching geospatial concepts with geographic educational needs. Geographical Research, v. 46, n. 1, p. 85-98, 2007. Disponível em: https://onlinelibrary.wiley.com/doi/abs/10.1111/j.1745-5871.2007.00494.x. Acesso em: 22 fev. 2021.

GOMES, P. C. C. Quadros geográficos: uma forma de ver, uma forma de pensar. Rio de Janeiro: Bertrand Brasil, 2017.

GOMES, P. C. C. Um lugar para a geografia: contra o simples, o banal e o doutrinário. In: MENDONÇA, F. A.; LOWEN-SAHR, C. L.; SILVA, M. (Org.). Espaço e tempo: complexidade e desafios do pensar e do fazer geográfico. Curitiba: Associação de Defesa do Meio Ambiente e Desenvolvimento Antonina, 2009. p. 13 -30.

GONZÁLEZ, R. M. Del pensamiento espacial al conocimiento geográfico a través del aprendizaje activo con tecnologías de la información geográfica. Giramundo - Revista de Geografia do Colégio Pedro II, v. 4, n. 2, p.7-13, 2015. Disponível em: https://www. cp2.g12.br/ojs/index.php/GIRAMUNDO/article/view/668. Acesso em: 22 fev. 2021.

HAESBAERT, R. O espaço como categoria e sua constelação de conceitos: uma abordagem didática. In: TONINI, I. M. T.; CASTROGIOVANNI, A. C.; GOULART, L. B.; KAERCHER, N. A.; MARTINS, R. E. M. W. (Org.). O ensino de geografia e suas composições curriculares. Porto Alegre: Mediação, 2014. p. 109-122.

LIBÂNEO, J. C. Didática e epistemologia: para além do embate entre a didática e as didáticas específicas. In: VEIGA, I. P. A.; D’ ÁVILA, C. (Org.). Profissão docente: novos sentidos, novas perspectivas. Campinas, SP: Papirus, 2008. p. 59-88.

MELAZZO, E. S.; CASTRO, C. A. A escala geográfica: noção, conceito ou teoria? Terra Livre, Presidente Prudente, v. 2, n. 29, p. 133-142, 2007. Disponível em: https://www. agb.org.br/publicacoes/index.php/terralivre/article/view/244. Acesso em: 22 fev. 2021.

MIRANDA ARREDONDO, P. Modelo de progresión del aprendizaje geográfico como proceso situado: aulas interculturales como caso de estudio. Tese (Doutorado em Educação) Facultad de Educación, Pontificia Universidad Católica de Chile, Santiago, 2016. Disponível em: https://repositorio.uc.cl/handle/11534/21511. Acesso em: 22 fev. 2021.

MORAES, A. C. R. Ideologias geográficas. São Paulo: Hucitec/Annablume, 2005. v. 1.

MOREIRA, R. Pensar e ser em geografia. 2. ed. São Paulo: Contexto, 2015.

MOREIRA, R. Geografia e práxis: a presença do espaço na teoria e na prática geográfica. São Paulo: Contexto, 2012.

OLIVEIRA, A. U. Espaço e tempo: compreensão materialista e dialética. In: SANTOS, M. (Org.). Novos rumos da geografia brasileira. São Paulo: Hucitec, 1988. p. 66-110.

RICHTER, D. Raciocínio geográfico e mapas mentais: a leitura espacial do cotidiano por alunos do Ensino Médio. Tese (Doutorado em Geografia) - Faculdade de Ciências e 
Tecnologia, Universidade Estadual Paulista, Presidente Prudente, 2010. Disponível em: https://repositorio.unesp.br/handle/11449/105074. Acesso em: 22 fev. 2021.

SANTOS, L. S. C.; SOUZA, V. C. Pensar e raciocinar: a geografia como instrumento de cognição. Signos Geográficos - Boletim NEPEG de Ensino de Geografia, v. 3, p. 1-19, 2021. Disponível em: https://www.revistas.ufg.br/signos/article/view/67379. Acesso em: 13 jul. 2021.

SANTOS, M. A natureza do espaço: técnica, razão e emoção. 4. ed. São Paulo: Edusp, 2017[1996].

SHULMAN, L. S. Conhecimento e ensino: fundamentos para a nova reforma. Trad. Leda Beck. Rev. téc. Paula Louzano. Cadernos Cenpec, São Paulo, v. 4, n. 2, p. 196-229, 2014. Disponível em: https://www2.uepg.br//programa-des/wp-content/uploads/ sites/32/2019/08/SHULMANN-sobre-ENSINO.pdf. Acesso em: 22 fev. 2021.

SMIRNOV, A. A.; RUBINSTEIN, S. L.; LEONTIE, A. N.; TIEPLOV, B. M. El pensamiento. Trad. Florencio Villa Landa. In: SMIRNOV, A. A.; RUBINSTEIN, S. L.; LEONTIE, A. N.; TIEPLOV, B. M. (Org.). Psicología. Ciudad de México: Grijalbo, 1969. cap. VIII. p. 232-275.

SOUZA, M. L. Os conceitos fundamentais da pesquisa sócio-espacial. Rio de Janeiro: Bertrand Brasil, 2016.

VIGOTSKI, L. S. A construção do pensamento e da linguagem. Trad. Paulo Bezerra. São Paulo: Martins Fontes, 2000.

Recebido em: 23 ago. 2021 Aprovado em: 14 set. 2021 